\title{
Absence of normal sexual dimorphism of the genitofemoral nerve spinal nucleus in the mutant cryptorchid (TS) rat
}

\author{
D. W. Goh, P. J. Farmer and J. M. Hutson* \\ Surgical Research Unit, Royal Children's Hospital, Flemington Road, Parkville, Victoria 3052, Australia
}

\begin{abstract}
Sexual dimorphism of the genitofemoral nerve spinal nucleus has been demonstrated in normal rodents. Calcitonin gene-related peptide is a neurotransmitter, present in the genitofemoral nerve, that has been implicated in the regulation of gubernacular migration and inguinoscrotal testicular descent. A combination of retrograde fluorescent labelling of the genitofemoral nerve and immunohistochemistry for calcitonin gene-related peptide was used in 1-3-day-old mutant TS rats with $85 \%$ incidence of congenital cryptorchidism and an absence of the normal sexual dimorphism of the genitofemoral nerve spinal nucleus was demonstrated. There was no significant difference between male and female nuclei with respect to fluorescent-labelled neurones as well as those immunoreactive for calcitonin gene-related peptide, in contrast to an obvious sexual dimorphism present in normal control animals. This lack of normal sexual dimorphism of the genitofemoral nerve nucleus is likely to be important in the pathogenesis of cryptorchidism in this animal model.
\end{abstract}

\section{Introduction}

Recent evidence supports the proposal of a biphasic model for testicular descent (Hutson, 1986; Fallat et al., 1992; Hutson et al., 1992), with the transabdominal phase controlled by Mullerian inhibiting substance (Hutson et al., 1987; 1990a, b) and the inguinoscrotal phase being dependent on androgens (Perez-Palacios and Joffe, 1972; Husmann and McPhaul, 1991a; Spencer ef al., 1991). An intact genitofemoral nerve (GFN) is essential for the inguinoscrotal phase to occur (Lewis, 1948; Beasley and Hutson, 1987; Fallat et al., 1992) and sexual dimorphism of the GFN spinal nucleus has been demonstrated in normal rodents (Kojima and Sano, 1984; Larkins et al., 1991).

The neurotransmitter calcitonin gene-related peptide (CGRP), which is expressed in the GFN, has been implicated as a likely mediator of this phase of descent (Larkins and Hutson, 1991; Larkins et al., 1991; Yamanaka et al., 1992). CGRP is a peptide containing 37 amino acids that is formed by tissuespecific alternative processing of the mRNA transcript of the calcitonin gene (Rosenfeld et al., 1983). Immunohistochemistry for CGRP has shown that the peptide is present throughout the spinal cords of humans and eight other species, including rodents, mainly in sensory neurones in the dorsal horn as well as in motor neurones in the ventral horn, particularly in the lumbar region (Gibson et al., 1984).

The mutant TS rat was originally described as having ectopic scrota (Ikadai et al., 1988). However, closer evaluation has revealed that the scrota in affected animals are in fact hypoplastic, but positioned normally. In $85 \%$ of males, the

${ }^{*}$ Correspondence.

Revised manuscript received 16 March 1994. testes are situated in a suprainguinal position in the superficial inguinal pouch, making this mutant a useful model for studying abnormalities of inguinoscrotal descent (Park and Hutson, 1991a). The aim of this study was to determine whether normal sexual dimorphism of the GFN spinal nucleus occurs in this rat, and retrograde fluorescent labelling was used together with immunohistochemistry for CGRP.

\section{Materials and Methods}

Retrograde fluorescent nerve labelling is a reliable method for labelling the central cell bodies of particular peripheral nerves (Kuypers et al., 1977; Larkins et al., 1991). Kar et al. (1990) demonstrated the specificity of the labelling by showing that positive labelling of the spinal nucleus of GFN occurs only when fluorescent dye is injected into this nerve but not when injected into the ureter, colon or the pudendal nerve.

\section{Animals}

TS rats (Imamichi Institute) with congenital suprainguinal ectopic testes (Ikadai et al., 1988; Park and Hutson, 1991a) were maintained at the Royal Children's Hospital, Melbourne. The adult rats were fed on Barastoc AR2 rat- and mouse-breeder cubes and water ad libitum, and kept in a constant photoperiod of $12 \mathrm{~h}$ light: $12 \mathrm{~h}$ dark. Seven male and seven female TS rats aged 1-3 days were studied. Gentle pressure on the abdomen enables the direction of gubernacular migration to be determined and therefore testicular descent or maldescent to be predicted (Park and Hutson, 1991a). Normal Sprague-Dawley rats ( 5 males and 5 females; $1-3$ days old) were used as control animals. 


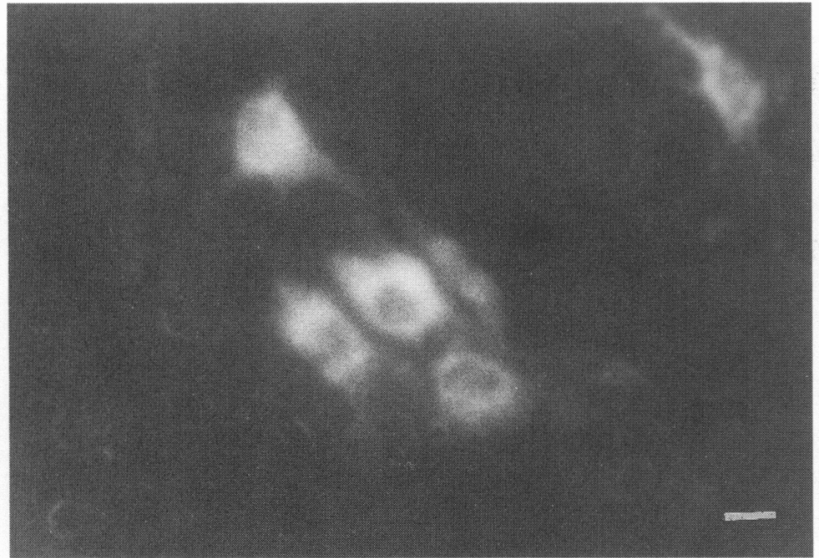

Fig. 1. Retrograde Fast Blue fluorescent labelling of neurones in the genitofemoral nerve spinal nucleus of TS rats. The photomicrograph shows cells with bright fluorescence and a clearly defined nucleus. Scale bar represents $10 \mu \mathrm{m}$.

\section{Fluorescent labelling of GFN}

The animals were anaesthetized with oxygen and $2 \%$ halothane, and laparotomy was performed just inferior to the umbilicus. The posterior peritoneum was incised inferior to the renal vessels bilaterally. The GFN on each side was identified on the psoas muscle and transected. Several crystals of Fast Blue (Sigma Chemical Co., St Louis, $\mathrm{MO}$ ) were applied to the proximal cut end of the nerve, and the peritoneum and bowel were returned to their normal positions. The abdominal wound was sutured with $6 / 0$ silk.

After they were maintained for $48 \mathrm{~h}$ to maximize retrograde transport of the fluorescent dye while minimizing leakage (Larkins and Hutson, 1991; Larkins et al., 1991), the animals were anaesthetized again. The thorax was opened and the inferior vena cava divided below a ligature. Transcardiac perfusion with $10 \mathrm{ml}$ normal saline was followed by adding $10 \mathrm{ml}$ Zamboni's fixative. The spinal cord was removed and stored in Zamboni's fixative for 3-7 days at $4^{\circ} \mathrm{C}$ before being cleared in dimethylsulfoxide and stored in PBS containing $30 \%$ $(\mathrm{w} / \mathrm{v})$ sucrose for $1-3$ days.

Tissues were embedded in OCT-embedding medium (Miles, Elkhart, IN) and frozen in isopentane over liquid nitrogen. Frozen serial sections, $25 \mu \mathrm{m}$ thick, were cut on to slides coated with a $1 \%$ gelatin mixture and left to dry.

The pattern of fluorescence was observed under an epifluorescence microscope (Leitz Diaplan). All sections were viewed, and only cells with bright fluorescence and a clearly defined nucleus (Fig. 1) were counted as positive to minimize errors of counting the same neurones more than once in serial sections (Konigsmark, 1970). Sections with fluorescent-labelled cells in the GFN nucleus in the ventral horn of the spinal cord were marked and selected for the next phase.

\section{CGRP immunohistochemistry}

The slides were incubated for $5 \mathrm{~min}$ with $3 \%$ hydrogen peroxide to quench endogenous peroxidase, and then preincubated with $10 \%$ normal sheep serum for $30 \mathrm{~min}$ to block

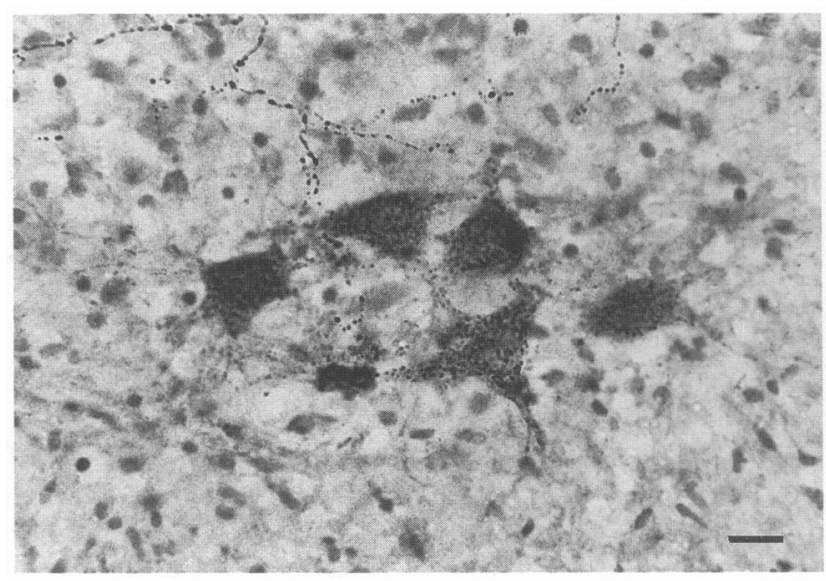

Fig. 2. Neurones in the genitofemoral nerve spinal nucleus of TS rats immunoreactive for calcitonin gene-related peptide (CGRP). The photomicrograph shows cells with strong CGRP immunoreactivity and a clearly defined nucleus. Scale bar represents $10 \mu \mathrm{m}$.

nonspecific staining. After removal of excess serum, slides were incubated overnight with a primary antibody raised in a rabbit against rat CGRP (Chemicon International Inc., El Segundo, CA; diluted 1:4000).

The next day, the slides were rinsed for $15 \mathrm{~min}$ in PBS and a biotinylated secondary antibody was added for $2 \mathrm{~h}$ (Amersham RPN 1400, donkey anti-rabbit antibody; diluted 1:200). The slides were rinsed and a streptavidin-biotin-peroxidase compiex (Amersham RPN 1051, 1:100) was added for $30 \mathrm{~min}$. After another rinse the substrate $3^{\prime}, 3^{\prime}$-diamidinobenzidine (Sigma Chemical Co.) was added for $10 \mathrm{~min}$ and the slides were counterstained with haematoxylin, and mounted in DPX ('DePex' mounting medium; BDH Chemicals, Kilsyth).

All sections were counted again and cells with strong CGRP immunoreactivity and a clearly defined nucleus were counted as positive (Fig. 2).

Negative controls included incubating the slides in either PBS alone or in antiserum with excess synthetic rat CGRP, instead of the primary antibody. Dorsal root ganglia served as a positive control for the expression of CGRP.

\section{Statistical analysis}

Statistical analysis was performed using the Mann-Whitney U test.

\section{Results}

Retrograde fluorescent labelling of the motor neurones of the GFN nucleus in the ventral horn of the spinal cord was consistently reproducible, and allowed quantification of the labelled neurones as well as identification and localization of the GFN nucleus for the quantification of CGRPimmunoreactive neurones.

Quantitative studies showed that in the TS rat there was no significant difference between male and female GFN nuclei either in terms of the number of neurones with Fast Blue fluorescence or in the number of neurones with CGRP 
(a)

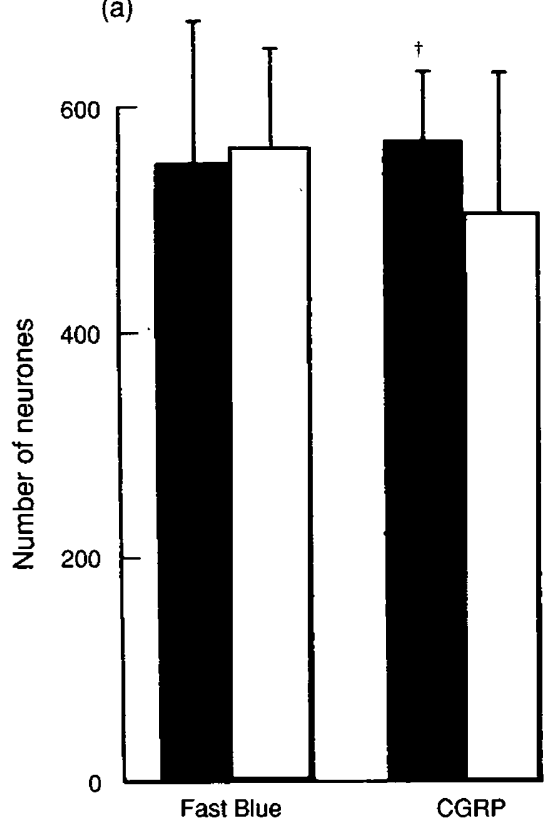

(b)

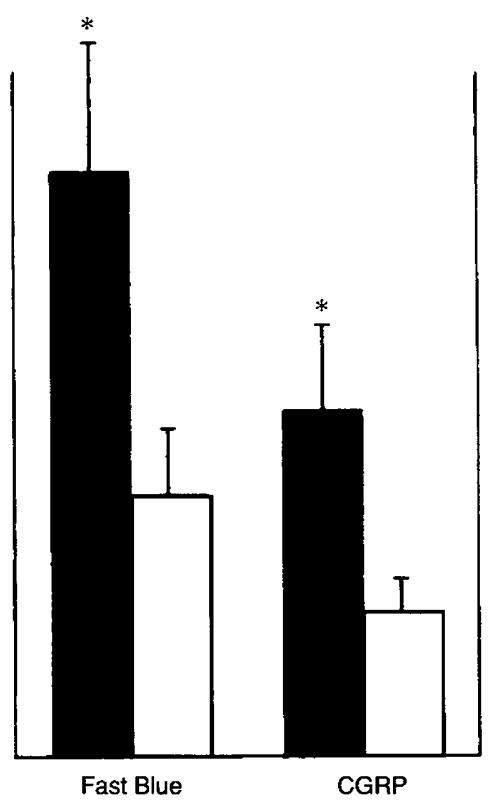

Fig. 3. Neurones labelled with Fast Blue and immunoreactive for calcitonin gene-related peptide (CGRP) in the genitofemoral nerve of male ( $\square$ ) and female ( $\square$ ) (a) TS rats $(n=14$ of each sex) and (b) control rats $(n=10$ of each sex). Bars represent the mean value $+1 \mathrm{sD}$. ${ }^{*} P<0.001$, compared with female rats; ${ }^{\dagger} P<0.001$, compared with normal rats.

Table 1. The mean ( $\pm \mathrm{SD}$ ) number of Fast-Blue-labelled and CGRP-immunoreactive neurones in genitofemoral (GFN) nuclei ipsilateral to predicted descended testes compared with undescended testes in TS rats

\begin{tabular}{lcc}
\hline & $\begin{array}{c}\text { Number of } \\
\text { Fast-Blue-labelled neurones }\end{array}$ & $\begin{array}{c}\text { Number of } \\
\text { CGRP-immunoreactive neurones }\end{array}$ \\
\hline Descended testes $(n=5$ GFN nuclei) & $556 \pm 129$ & $563 \pm 33$ \\
Undescended testes & $546 \pm 131$ & $571 \pm 75$ \\
\hline
\end{tabular}

No significant difference was observed between nuclei ipsilateral to descended testes compared with undescended testes for both Fast-Blue-labelled and CGRP-immunoreactive neurones.

CGRP: calcitonin gene-related peptide.

immunoreactivity. In addition, in males and females, there was no significant difference between the number of neurones with Fast Blue fluorescence and the number of neurones with CGRP immunoreactivity in the GFN nucleus. In normal control rats, however, male GFN nuclei contained more than twice as many fluorescent-labelled $(P<0.001)$ and CGRP-immunoreactive neurones $(P<0.001)$ compared with female GFN nuclei (Fig. 3).

GFN nuclei ipsilateral to the predicted undescended testes were compared with the nuclei ipsilateral to predicted descended testes. There was no significant difference between these two groups of nuclei, either in terms of fluorescentlabelled neurones or CGRP-immunoreactive neurones (Table 1 ).

\section{Discussion}

In the mutant TS rat (Ikadai et al., 1988) $85 \%$ of males have congenital cryptorchidism (Park and Hutson, 1991). The un- descended testes, uni- or bilateral, are situated suprainguinally in a superficial inguinal pouch, which is almost identical to the commonest form of human cryptorchidism (Park and Hutson, 1991). Apart from the undescended testes, these rats are phenotypically normal males and there are no differences in serum testosterone and $\mathrm{LH}$ concentrations among normal, unior bilaterally affected rats. Serum FSH concentrations are higher in bilaterally affected rats compared with normal rats (Ikadai et al., 1988). Affected (undescended) testes in mature rats show severe degenerative changes, and spermatogenesis is arrested at the primary spermatocyte stage (Ikadai et al.,1988).

Sexual dimorphism of particular regions of the central nervous system has been described (Raisman and Field, 1973; Nottebohm and Arnold, 1976), including the sexually dimorphic nuclei of the bulbocavernosus muscle and the ischiocavernosus muscle (Jordan et al., 1982; Breedlove and Arnold, 1983). This sexual dimorphism appears to be androgendependent (Jordan et al., 1982), the androgens causing 
'masculinization' of the nuclei in the prenatal period. However, such sexual dimorphism can be obliterated by prenatal treatment with the anti-androgen flutamide (Breedlove and Amold, 1983). Sexual dimorphism has also been demonstrated in the GFN spinal nucleus in normal rodents (Kojima and Sano, 1984; Larkins et al., 1991). The GFN nucleus in normal neonatal male rodents has been shown by Larkins et al. (1991) to be twice as large and to have four times as many CGRP-positive neurones than those in females.

This study has shown that this normal sexual dimorphism of the GFN nucleus is absent in TS rats. There is no significant difference between males and females both in terms of numbers of fluorescent-labelled neurones and in numbers of CGRPimmunoreactive neurones in the GFN nucleus. Although only approximately half of the fluorescent-labelled neurones are CGRP-immunoreactive in normal rats, the numbers of fluorescent-labelled and CGRP-immunoreactive neurones are not significantly different in male and female TS rats. Therefore, there is an abnormally high proportion, as well as higher absolute numbers, of CGRP-immunoreactive neurones in the GFN nucleus of the TS rat. These abnormalities are likely to be of significance in the failure of inguinoscrotal testicular descent in this rat.

While the issue remains controversial (Spencer et al., 1992), recent evidence suggests that testicular descent may occur by a biphasic mode (Hutson et al., 1990b, 1992). The first, or transabdominal, phase may be controlled by Mullerian inhibiting substance (Hutson, 1986; Hutson et al., 1987; 1990a), while the second, or inguinoscrotal, phase appears to be dependent on androgens (Husmann and McPhaul, 1991a; Spencer et al., 1991). The other factors that appear to be crucial for inguinoscrotal testicular descent are an intact GFN (Lewis, 1948; Beasley and Hutson, 1987) and gubernacular migration into the scrotum (Heyns, 1987; Fallat et al., 1992).

It has recently been proposed that androgens may act indirectly by causing masculinization of the GFN spinal nucleus in the prenatal period (Hutson and Beasley, 1987). The masculinized GFN containing appropriate quantities of CGRP could then provide directional, chemotactic guidance via its scrotal branches for gubernacular migration and inguinoscrotal testicular descent to occur along a concentration gradient of CGRP (Larkins and Hutson, 1991; Larkins et al., 1991; Hutson et al., 1992). The presence of high-affinity CGRP receptors in the gubernaculum lends support to this hypothesis of CGRP acting as a 'second messenger' for androgens in effecting inguinoscrotal testicular descent (Yamanaka et al, 1992).

Accordingly, the absence of sexual dimorphism of the GFN nucleus in the TS rat may account for the aberrant gubernacular migration and ectopic testes. It is not currently known why the normal sexual dimorphism is absent, as the males appear phenotypically normal with no evidence of androgen deficiency or insensitivity (Ikadai et al., 1988).

A puzzling finding in relation to the testicular maldescent is the excessively high proportion of CGRP-positive cells in the GFN nucleus in both sexes of TS rats compared with normal rodents. A plausible explanation is that excessive amounts of CGRP in the branches of the GFN may obliterate the normal concentration gradient of CGRP, and thereby obscure the directional guidance normally available to the gubernaculum during its migration.
The fact that no difference was found between GFN nuclei ipsilateral to predicted undescended testes and descended ones indicates that the primary defect acts systemically on the central nervous system, resulting in bilateral absence of sexual dimorphism of the GFN. In the absence of clear, directional chemotactic guidance from the GFN, local factors may supervene to influence the direction of gubernacular migration and the final testicular position.

In conclusion, an absence of normal sexual dimorphism of the GFN spinal nucleus has been demonstrated in the TS rat. This defect is likely to be of significance in the pathogenesis of undescended testes in this rat and is further evidence of the pivotal role of the GFN in the regulation of inguinoscrotal testicular descent.

The authors thank M. Sourial and K. Behrend for their patience and assistance with caring for the animals.

\section{References}

Beasley SW and Hutson JM (1987) Effect of division of genitofemoral nerve on testicular descent in the rat Australian and New Zealand Journal of Surgery 51 49-51

Breedlove SM and Arnold AP (1983) Hormonal control of a developing neuromuscular system. I. Complete demasculinization of the male rat spinal nucleus of the bulbocavernosus using the anti-androgen flutamide Journal of Neuroscience 3 417-423

Fallat ME, Williams MPL, Farmer PJ and Hutson JM (1992) Histologic evaluation of inguinoscrotal migration of the gubernaculum in rodents during testicular descent and its relationship to the genitofemoral nerve Pediatric Surgery International 7 265-270

Gibson SJ, Polak JM, Bloom SR, Sabate IM, Mulderry PM, Ghatei MA, McGregor GP, Morrison JFB, Kelly JS, Evans RM and Rosenfeld MG (1984) Calcitonin gene-related peptide immunoreactivity in the spinal cord of Man and eight other species Journal of Neuroscience 4 3101-3111

Heyns CJ (1987) The gubernaculum during testicular descent in the human fetus Joumal of Anatomy 153 93-112

Husmann DA and McPhaul MJ (1991) Time-specific androgen blockade with flutamide inhibits testicular descent in the rat Endocrinology $\mathbf{1 2 9}$ 1409-1416

Hutson JM (1986) Testicular feminization: a model for testicular descent in mice and men Journal of Pediatric Surgery 21 195-198

Hutson IM and Beasley SW (1987) The mechanisms of testicular descent Australian Paediatric Journal 23 215-216

Hutson JM, Chow CW and Ng WD (1987) Persistent Mullerian duct syndrome with transverse testicular ectopia. An experiment of nature with clues for understanding testicular descent Pediatric Surgery International 2 191-194

Hutson JM, Watts LM, Montalto J and Greco S (1990a) Both gonadotropin and testosterone fail to reverse estrogen-induced cryptorchidism in fetal mice: further evidence for non-androgenic control of testicular descent in the fetus Pediatric Surgery International 5 13-18

Hutson JM, Williams MPL, Fallat ME and Attah A (1990b) Testicular descent: new insights into its hormonal control. Oxford Reviews of Reproductive Biology $121-56$

Hutson JM, Baker ML, Griffiths AL, Momose Y, Goh DW, Middlesworth W, Zhou $B$ and Cartwright E (1992) Endocrine and morphological perspectives in testicular descent Reproductive Medicine Review 1 165-177

Ikadai H, Ajisawa C, Taya K and Imamichi T (1988) Suprainguinal ectopic scrota of TS inbred rats Journal of Reproduction and Fertility 84 701-707

Jordan CL, Breedlove SM and Arnold AP (1982) Sexual dimorphism and the influence of neonatal androgen in the dorsolateral motor nucleus of the rat lumbar spinal cord Brain Research 249 309-314

Kar S, Gibson SJ and Polak JM (1990) Origins and projections of peptideimmunoreactive nerves in the male rat genitofemoral nerve Brain Research $512 \quad 229-237$

Kojima M and Sano Y (1984) Sexual differences in the topographical distribution of serotonergic fibres in the anterior column of the rat lumbar spinal cord Anatomy and Embryology $\mathbf{1 7 0} 117-121$ 
Konigsmark BW (1970) Methods for the counting of neurons. In Contemporary Research Methods in Neuroanatomy pp 315-340 Eds WJH Nauta and SOE Ebbeson. Springer-Verlag, New York

Kuypers HG, Catsman-Berrevoets CE, Padt RE (1977) Retrograde axonal transport of fluorescent substances in the rat's forebrain Neuroscience Letters 6 $127-135$

Larkins SL and Hutson JM (1991) Fluorescent anterograde labelling of the genitofemoral nerve shows that it supplies the scrotal region before migration of the gubernaculum Pediatric Surgery International 6 167-171

Larkins SL, Hutson JM and Williams MPL (1991) Localisation of calcitonin gene-related peptide immunoreactivity within the spinal nucleus of the genitofemoral nerve Pediatric Surgery International 6 176-179

Lewis LG (1948) Cryptorchidism Joumal of Urology 60 345-346

Nottebohm F and Arnold AP (1976) Sexual dimorphism in vocal control areas of the songbird brain Science 194 211-213

Park W-H and Hutson JM (1991) A new inbred rat strain (TS) with suprainguinal ectopic testes: a model for human cryptorchidism Pediatric Surgery Intemational 6 172-175
Perez-Palacios G and Joffe RB (1972) The syndrome of testicular feminization Pediatric Clinics of North America $19653-667$

Raisman G and Field PM (1973) Sexual dimorphism in the neuropil of the preoptic area of the rat and its dependence on neonatal androgen Brain Research 54 1-29

Rosenfeld MG, Mermod JJ, Amara SG, Swanson LW, Sawchenko PE, Rivier J, Vale WW and Evans RM (1983) Production of a novel neuropeptide encoded by the calcitonin gene via tissue-specific RNA processing Nature 304 129-135

Spencer JR, Torrado T, Sanchez RS, Vaughan ED, Jr and Imperato-McGinley J (1991) Effects of tlutamide and finasteride on rat testicular descent Endocrinology 129 741-748

Spencer JR, Heyns CF, Hutson JM, Husmann DA, van Vlissingen JMF and van der Schoot P (1992) Mechanisms of testicular descent Dialogues in Pediatric Urology 15 1-8

Yamanaka J, Metcalfe SA and Hutson JM (1992) Demonstration of calcitoningene related peptide receptors in the gubernaculum by computerized densitometry Journal of Pediatric Surgery 27 876-878 